\title{
Special precautions in oral and maxillofacial surgeries regarding COVID-19 transmission
}

Matheus Francisco Barros Rodrigues, ${ }^{1}$ Layla Louise de Amorim Rocha, ${ }^{2}$ Rodrigo da Franca Acioly, ${ }^{3}$ Dennis Dinelly de Souza, ${ }^{4}$ Daniel do Carmo Carvalho, ${ }^{5}$ Rimsky Coelho Lopes da Rocha, ${ }^{6}$ and Cristofe Coelho Lopes da Rocha ${ }^{7}$

${ }^{1,2}$ Dentistry Course, Faculdade Cathedral, Boa Vista 69307-053, Brazil.

3,4,5 Department of Oral and Maxillofacial Surgery and Traumatology, Hospital Geral, Boa Vista 69305-455, Brazil.

${ }^{6}$ Center for Dental Research, São Leopoldo Mandic, Campinas 13045-755, Brazil.

${ }^{7}$ Infrastructure Department, Instituto Federal, Boa Vista 69303-340, Brazil.

Correspondence should be addressed to Matheus Francisco Barros Rodrigues; matheusfbr18@gmail.com

Key words: Coronavirus disease 2019 (COVID-19); Oral and maxillofacial; Urgency and emergency;

\begin{abstract}
The World Health Organization has defined the outbreak of the new coronavirus as a public health emergency of international concern. The average age of patients affected by the disease caused by the virus ranges from 49 to 59 years. The symptoms of coronavirus disease 2019 (COVID-19) infection include fever, cough, acute respiratory disease, and, in severe cases, the disease may progress to pneumonia and renal failure that may lead to death. Many oral and maxillofacial hospital procedures produce aerosol and droplets contaminated by blood, bacteria, and viruses. The purpose of this study is to gather recommendations from health authorities and scientific articles in order to educate surgeons regarding the procedures to assist and treat in oral and maxillofacial surgeries. The objective is to prevent the transmission of COVID-19 during the treatment of patients in urgent and emergency situations. The study's methodology used the guidelines provided by the Brazilian College of Oral and Maxillofacial Surgery, in addition to the recommendations and epidemiologic data from national and international health authorities. The implementation of special precautions in oral and maxillofacial surgeries may elucidate questions related to the transmission of the disease by asymptomatic carriers and help control the spread of the virus.
\end{abstract}

\section{Introduction}

In December 2019, several cases of pneumonia of unknown cause were reported in Wuhan, China $[1,2]$. The most likely source of the outbreak was a virus transmitted by bats as well as pangolins, an intermediate host animal [3]. However, some characteristics of the virus are still unknown [4]. One month later, scientists identified the cause: a new type of coronavirus [1].

The new coronavirus was initially called 2019-nCoV, and it was subsequently officially named severe acute respiratory syndrome coronavirus 2 (SARS-CoV-2). The disease caused by the new coronavirus was named COVID-19 and was acknowledged in 34 countries [3, 5]. 
On January 31, 2020, the World Health Organization (WHO) ${ }^{1}$ defined the outbreak of the new coronavirus as a public health emergency of international concern $[1,2,3,4,6]$. The disease spread to several regions of the world, reaching Latin America on February 25, 2020, when the Brazilian Ministry of Health confirmed the first case. The average age of patients affected by the disease ranges from 49 to 59 years, and it was rarely found in young people under the age of 15 [7].

According to the Brazilian Ministry of Health, by April 3, 2020, 9,056 cases of COVID19 were confirmed, as shown in Chart 1.

Chart 1: COVID-19 cases confirmed daily in Brazil

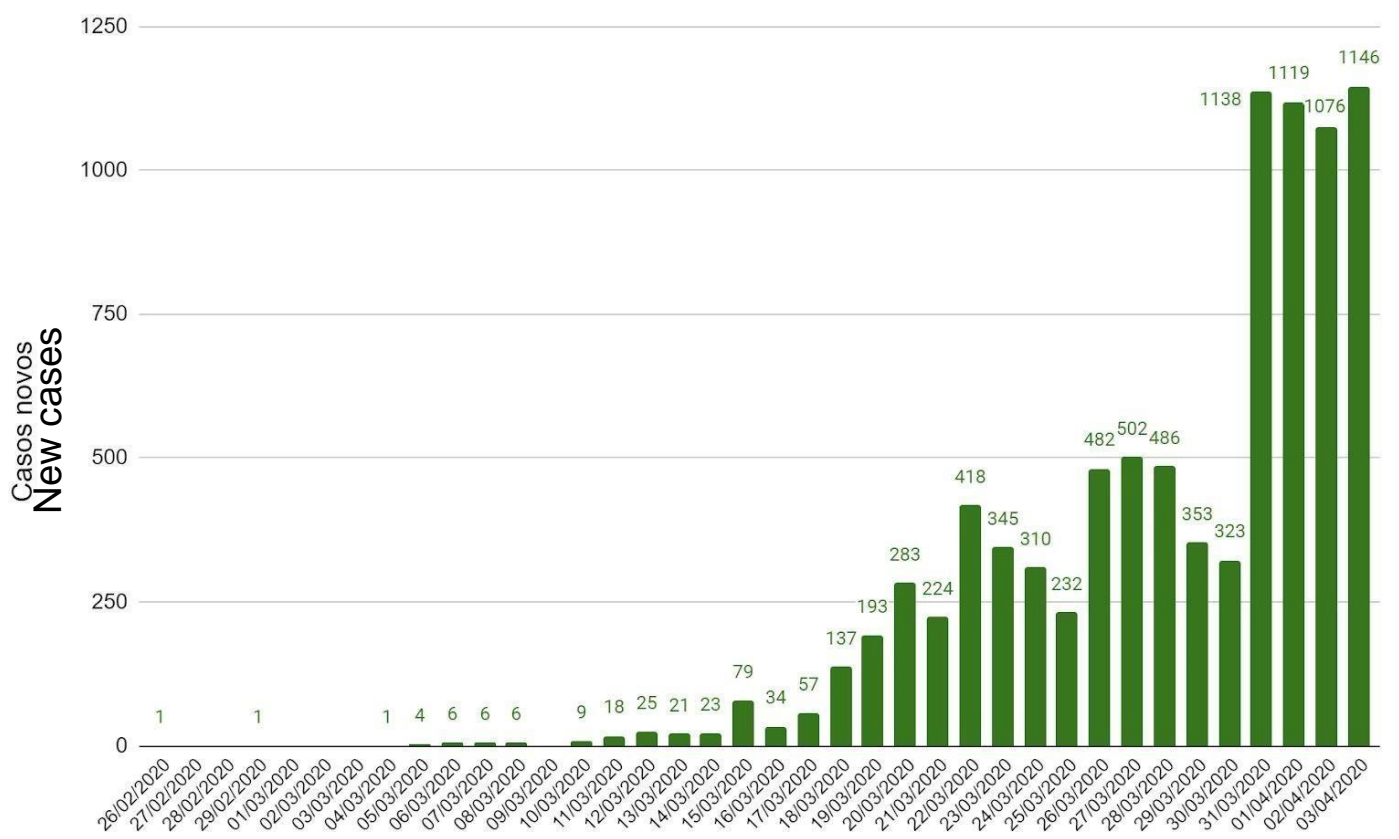

Source: Epidemiological report from the public health emergency operations center, April 3, 2020, Secretariat of Health Surveillance/Ministry of Health. Available https://portalarquivos.saude.gov.br/images/pdf/2020/April/03/BE6-Boletim- Especial-do-COE.pdf

Most cases of the disease present with relatively mild symptoms, and according to data from the National Health Commission of the People's Republic of China (PRC) ${ }^{2}$, the proportion of serious cases in China was about $15 \%$ to $25 \%$ [3, 8, 9]. Symptoms of COVID-19 infection include fever, cough, and acute respiratory disease, while severe cases may develop into pneumonia and renal failure that may even lead to the death of the patient $[4,5]$. Advanced age and the existence of underlying comorbidities (diabetes, hypertension, and vascular diseases) are associated with the worst prognoses [3]. The incubation period was estimated to be between five to six days on average, and may last up to 14 days. The duration is commonly adopted for medical observation during quarantine [3]. During the incubation period, transmission can occur before symptoms appear [4].

The transmission routes of COVID-19 have yet to be identified. However, human-tohuman transmission has been confirmed [4] and interpersonal transmission is believed to occur primarily through respiratory droplets (expelled during speech, coughing, or sneezing) and direct

\footnotetext{
${ }_{1}^{1} \mathrm{WHO}$ is based in Geneva, Switzerland, and was established on April 7, 1948. Available at: https://www.who.int/home

2 The National Health Commission of the PRC is responsible for drafting laws and regulations for national health policies in the Republic of China. Available at: http://en.nhc.gov.cn/
} 
contact with infected people $[1,2,3]$. In addition, there may be a risk of fecal-oral transmission [3].

Recently, SARS-CoV-2 was found in the saliva of infected patients $[4,10]$. The studies by Wang et al. (2004) further reinforced the possibility of transmission through oral droplets, due to the large amount of SARS-CoV RNA found in saliva [11]. It is important that oral healthcare professionals are attentive to avoid spreading SARS-CoV-2 [4], as the virus can survive on hands, objects, and surfaces that have been infected by saliva for up to nine days [6].

Many oral and maxillofacial procedures performed in the hospital produce aerosols and droplets contaminated by blood, bacteria, and viruses [1]. Inhaling aerosol particles produced by a patient with COVID-19 represents a high risk of cross-infection between surgeons and patients $[2,3,4]$. The purpose of this study is to gather recommendations from health authorities and scientific articles in order to educate surgeons about procedures to reduce the transmission of COVID-19 during oral and maxillofacial surgery and trauma (OMFST), particularly involving patients in urgent and emergency situations.

\section{Materials and Methods}

Recommendations from the Brazilian College of Oral and Maxillofacial Surgery and Trauma, the Brazilian Ministry of Health, the WHO, the National Health Surveillance Agency $(\text { ANVISA) })^{3}$, the Brazilian Council of Dentistry (CFO), and the National Health Commission of the PRC were compiled for use related to precautions in OMFST procedures against the transmission of COVID-19. Research was carried out in Scielo, Pubmed, Google Scholar, and Portal de Periódicos da Capes databases to gather information about the history of SARS CoV-2 in order to recognize its characteristics and transmission routes. The approach of this study focused on precautionary measures with the purpose of elucidating questions related to COVID-19 transmission through droplets of saliva and aerosols in hospital environments within the scope of oral and maxillofacial surgery in urgent and emergency procedures.

\section{Contamination via saliva and aerosol in oral and maxillofacial surgery}

Otter et al. (2013) found that contaminated surfaces are a route of transmission for various nosocomial pathogens [12]. When a person coughs, sneezes, laughs or talks, large droplets of saliva larger than $5 \mu \mathrm{m}$ in diameter, as well as small aerosol droplets less than or equal to $5 \mu \mathrm{min}$ diameter, are generated [2], as shown in Figure 1.

The particles can follow different routes of transmission through droplets, aerosols, or even surfaces contaminated during a surgical procedure. The large droplets reach shorter distances (represented by the close proximity arrow in Figure 1) and fall quickly to the ground due to gravitational force. Contamination by these droplets requires greater proximity between the infected individual and a susceptible person [2]. Small aerosol droplets have a low sedimentation speed and can travel longer distances (represented by the further distance arrow in Figure 1) before entering the respiratory tract or contaminating objects [2]. Some measures can be adopted to reduce the risk of contamination, such as continuous aspiration of saliva and use of mouthwash in

\footnotetext{
${ }^{3}$ ANVISA is part of the Emergency Operations Center (COE) - Coronavirus, instituted by the Brazilian Ministry of Health. Technical note available at: http://portal.anvisa.gov.br/documents/33852/271858/ Nota+Técnica+n+04-2020+GVIMS-GGTES-ANVISA/ab598660-3de4-4f14-8e6f-b9341c196b28
} 
order to reduce the viral load. Intensive care unit (ICU) patients are suggested to use $0.5 \%$ to $1 \%$ hydrogen peroxide or $0.2 \%$ povidone [13].

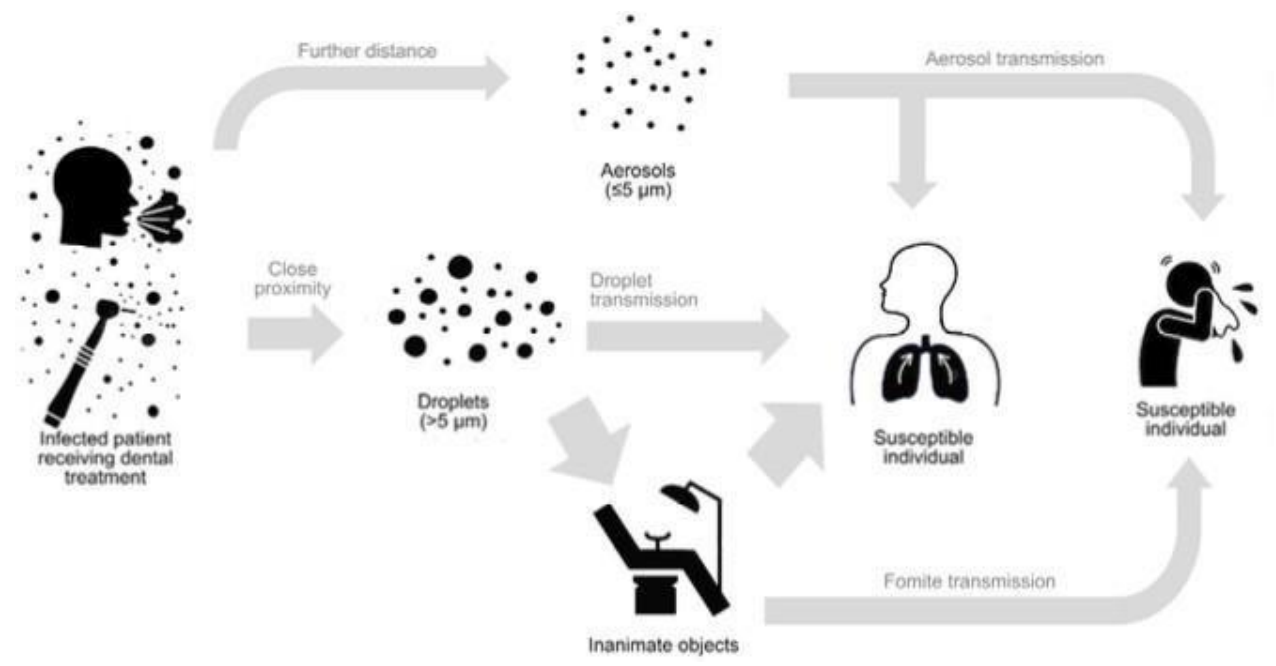

Figure 1: Different routes of transmission of COVID-19 [2]

During oral and maxillofacial surgery procedures that utilize high-speed hand pieces and abundant irrigation, bodily fluids from the oral cavity, such as blood and saliva, produce aerosols. The procedure further increases the transmission capacity for susceptible individuals, as shown in Figure 1 in the aerosol transmission arrow [2].

Often, oral and maxillofacial procedures are performed in hospital environments on an urgent and emergency basis. It is important for the procedures used during treatment to include precautionary measures. Specific precautionary recommendations have been indicated due to the current COVID-19 crisis.

\section{Precautions in oral and maxillofacial surgeries}

During hospital care, some conditions are considered to be of an emergency nature, posing life-threatening risks for the patient. Some of these conditions include uncontrolled bleeding, cellulitis, or diffuse bacterial infections with increased volume (edema) of intraoral or extraoral location and potential risk of compromising the patient's airway, and trauma involving the facial bones with potential impairment of the patient's airway [14]. In contrast, urgent conditions are routinely treated by the oral and maxillofacial surgeon and, although there is no imminent risk of death for these conditions, some special precautions must be observed in order to reduce the risk of disease transmission [14].

During oral and maxillofacial surgical practice, some technical guidelines are followed as standard precautions for infection control. Due to the epidemiological outbreak of COVID-19, some special precautions were added as a means of prevention [2].

Table 1 was created based on ANVISA's recommendations in association with the Brazilian Council of Dentistry (CFO), Brazilian College of Oral and Maxillofacial Surgery and Trauma, and the Association of Brazilian Intensive Medicine (AMIB), together with CFO. It describes precautions for urgent and emergency situations in patients with or without suspicion 
for COVID-19, in addition to confirmed patients. The special precautions column describes the procedures to be adopted by the surgeons and their team in each situation.

Table 1: Situation and special precautions for treatment in OMFST procedures

\begin{tabular}{|c|c|}
\hline $\begin{array}{r}\text { Patient status for COVID- } \\
\text { 19/treatment }\end{array}$ & Special precautions \\
\hline No suspicion/Elective & $\begin{array}{l}\text { Temporary suspension of elective } \\
\text { procedures [13]. The treatment should be } \\
\text { postponed due to the COVID-19 } \\
\text { epidemic }[14,15] .\end{array}$ \\
\hline Suspicion/Elective & $\begin{array}{l}\text { The treatment should be postponed and } \\
\text { the patient with suspected COVID-19 } \\
\text { should be instructed to be in home } \\
\text { isolation immediately and seek medical } \\
\text { care only if symptoms worsen [13]. }\end{array}$ \\
\hline No suspicion/Urgent and Emergency & $\begin{array}{l}\text { The treatment should be performed with } \\
\text { standard caution using personal protective } \\
\text { equipment (PPE) and additional to the } \\
\text { whole team [13]. }\end{array}$ \\
\hline Suspicion/Urgent and Emergency & $\begin{array}{l}\text { The treatment should be performed with } \\
\text { standard caution and additional to the } \\
\text { whole team [13]. }\end{array}$ \\
\hline Positive/Urgent and Emergency & $\begin{array}{l}\text { Requires immediate treatment in } \\
\text { hospital and/or clinic care where there is } \\
\text { appropriate PPE [15]. }\end{array}$ \\
\hline
\end{tabular}

During the execution of urgent and emergency procedures in a hospital environment, PPE should be worn, such as a hat, goggles, face shield, waterproof apron, procedure gloves, and N95/PFF2 mask or equivalent [14]. However, it is important to note that some tests and procedures require greater precautions on the part of the oral and maxillofacial surgeons and their teams. The rationale is to reduce the risk of contamination through oral and respiratory secretions in patients suspected or diagnosed with COVID-19 [14].

For example, the oroscopy exam is recommended to only be carried out at the request of a doctor and on an urgent and emergency basis. Radiography should preferably be extraoral [14]. Intraoperative measures that limit the generation of aerosols should be adopted. In case of intubation, the team should be outside the room for up to 20 minutes after the procedure, and it is preferable for the procedure to be performed by the most experienced team member [15]. 
Additionally, Ge et al. (2020) discuss strategies to reduce droplet generation in oral and maxillofacial surgery practices. They add that when performing a simple extraction, the surgeon must position the patient in the supine position to avoid direct contact with the patient's airway [2].

\section{Final Considerations}

Oral and maxillofacial surgeons, by nature, are at high risk of exposure to infectious diseases. The COVID-19 outbreak has brought us new challenges and a better understanding of SARS-CoV-2 transmission through saliva and aerosol droplets. Furthermore, the implications COVID-19 has in oral and maxillofacial surgeries may represent an aid in identifying and correcting existing negligence in daily practice. In addition to standard precautions, the implementation of special precautions may prevent the transmission of COVID-19 by asymptomatic carriers, and help control the spread of the virus. In addition, the outbreak has triggered fresh analysis of previous procedures for urgent and emergency cases that are deemed necessary.

\section{Conflict of Interest} document.

The authors declare there is no conflict of interest in relation to the publication of this

\section{Acknowledgements}

We would like to thank the Brazilian College of Oral and Maxillofacial Surgery (Colégio Brasileiro de Cirurgia e Traumatologia Buco-Maxilo-Facial), as well as the translation agency, H3 Traduções.

\section{References}

[1] Guo, Huaqiu, et al. "The impact of the COVID-19 epidemic on the utilization of emergency dental services." Journal of Dental Sciences (2020).

[2] Ge, Zi-yu, et al. "Possible aerosol transmission of COVID-19 and special precautions in dentistry." Journal of Zhejiang University-SCIENCE B (2020): 1-8.

[3] Meng, L., F. Hua, and Z. Bian. "Coronavirus Disease 2019 (COVID-19): Emerging and Future Challenges for Dental and Oral Medicine." Journal of Dental Research (2020): 0022034520914246.

[4] Sabino-Silva, Robinson, Ana Carolina Gomes Jardim, and Walter L. Siqueira. " Coronavirus COVID- 19 impacts to dentistry and potential salivary diagnosis." Clinical Oral Investigations (2020): 1-3.

[5] de Campos Tuñas, Inger Teixeira, et al. "Doença pelo Coronavírus 2019 (COVID-19): Uma abordagem preventiva para Odontologia." Revista Brasileira de Odontologia 77 (2020).

[6] Spagnuolo, Gianrico, et al. "COVID-19 Outbreak: An Overview on Dentistry." (2020): 2094.

[7] Kamer, Erdinç and Çolak, Tahsin. "What to Do When A Patient Infected With COVID-19 Needs An Operation: A Pre-surgery, Peri-surgery and Post-surgery Guide.” Turkish Journal of Colorectal Disease 30 (2020):1-8. 
[8] Guan, Wei-jie, et al. "Clinical characteristics of 2019 novel coronavirus infection in China." MedRxiv (2020).

[9] Yang, Yang, et al. "Epidemiological and clinical features of the 2019 novel coronavirus outbreak in China." medRxiv (2020).

[10] To, Kelvin Kai-Wang, et al. "Temporal profiles of viral load in posterior oropharyngeal saliva samples and serum antibody responses during infection by SARS-CoV-2: an observational cohort study." The Lancet Infectious Diseases (2020).

[11] Wang, Wei-Kung, et al. "Detection of SARS-associated coronavirus in throat wash and saliva in early diagnosis." Emerging infectious diseases 10.7 (2004): 1213.

[12] Otter, Jonathan A., et al. "Evidence that contaminated surfaces contribute to the transmission of hospital pathogens and an overview of strategies to address contaminated surfaces in hospital settings." American journal of infection control 41.5 (2013): S6-S11.

[13] Recomendações, A. M. I. B., and C. F. O. para atendimento odontológico COVID. "Comitê de Odontologia AMIB/CFO de enfrentamento ao COVID-19 Departamento de Odontologia AMIB-1 Atualização 25/03/2020."

[14] Novas recomendaççoes da ANVISA contam com colaboração do CFO para enfretamento da COVID-19 na Odontologia. Portal Conselho Federal de Odontologia - CFO, Brasília, 01 de abr. de 2020. Disponível em: < http://website.cfo.org.br/ novas-recomendacoes-da-anvisa-contam-com-colaboracao-do-cfo-para- enfrentamentoda-covid-19-na-odontologia/>. Acesso em: 08 de abr. de 2020.

[15] COVID-19 - Guia de Práticas em CTBMF. Portal do Colégio Brasileiro de Cirurgia e Traumatologia Bucomaxilo-facial, Brasília, 30 de mar. de 2020. Disponível em: < https://www.bucomaxilo.org.br/site/noticiasdetalhes.php?cod=344\&q=COVID-19+ +Guia+de+Pr\%C3\%A1ticas+em+CTBMF\&bsc=ativar >. Acesso em: 07 de abr. de 2020. 